\title{
REPLY
}

\section{Case report by RN Mohapatra: urine leakage in persons with spinal cord injury and using long-term Foley catheters: a simple solution}

Spinal Cord (2011) 49, 764; doi:10.1038/sc.2010.183;

published online 21 December 2010

It is salutary that Mohapatra should draw attention to the leakage of urine around the Foley catheter in spinal cord injury patients. He states:

'This case report highlights a common, but not often considered, cause of chronic leakage, and a simple effective solution. The persistence of small volumes of residual urine around the Foley catheter should be recognised as a possible source of persistent urine leakage around the catheter'.

This source of error was first described by Cook in $1960 .^{1}$ Cook showed that, in the recumbent position, urine pools at the back of the bladder and, despite washing through an indwelling Foley catheter, all the urine is not obtained. Once the patient is sat up, however, further urine can be drained. These findings were confirmed by Doggart et al. ${ }^{2}$ in 1966 , who carried out similar studies on 20 paraplegic patients and found that when patients stood up, after a conventional urine check, as much as $16 \mathrm{ml}$ of urine could be obtained.
These findings are well documented by Tribe and Silver ${ }^{3}$ and Guttmann. ${ }^{4}$

\section{Conflict of interest}

The author declares no conflict of interest.

JR Silver

Wendover, Buckinghamshire, UK E-mail: jrussellsilver@btconnect.com

\section{References}

1 Cook JB. The paralysed bladder. The residual urine in bladder rehabilitation. Proc Roy Soc Med 1960; 53: 263.

2 Doggart JR, Guttmann L, Silver JR. Comparative studies on endogenous creatinine and urea clearances in paraplegics and tetraplegics. Paraplegia 1966; 1: 202.

3 Tribe CR, Silver JR. Renal Failure in Paraplegia. Pitman Medical. London, 1969, pp 23.

4 Guttmann L. Spinal Cord Injuries: Comprehensive Management and Research. Blackwell Scientific Publications: Oxford, 1973, pp 349. 